ORIGINAL ARTICLE

\title{
Impact of congenital colour vision defects on occupation
}

\author{
P Cumberland, J S Rahi, C S Peckham
}

See end of article for authors' affiliations

.....................

Correspondence to: Dr J S Rahi, Centre for Paediatric Epidemiology and Biostatistics, Institute of Child Health, 30 Guilford Street, London WCIN $\mathrm{IEH}, \mathrm{UK}$;

i.rahi@ich.ucl.ac.uk

Accepted 18 May 2005

Published Online First

24 May 2005 Aims: To investigate whether there is an association between congenital colour vision defects (CVD) and
occupational choice and employment history, in order to inform the debate about the value of universal childhood screening for these disorders.

Methods: Participants were 6422 males and 6112 females from the 1958 British birth cohort, followed from birth to 33 years, whose colour vision was assessed (Ishihara test) at 11 years.

Results: A total of 431 males (6.7\%) had CVD. Men with CVD had pursued some careers for which normal colour vision is currently regarded as essential; for example, eight men (3.1\%) with CVD were in the police, armed forces, or fire-fighting service at 33 years compared to 141 men (3.8\%) with normal colour vision. They were, however, under-represented compared to those with normal colour vision, in other occupations; for example, no men with CVD were employed in electrical and electronic engineering at 33 years compared to 15 men $(0.4 \%)$ with normal colour vision.

Conclusions: The findings of this study suggest there is little to be gained by continuing with existing school screening programmes for CVD, whose primary purpose is to advise affected children against certain careers. Other ways of informing young people about potential occupational difficulties and pathways for referral for specialist assessment are likely to be more useful.
$\mathrm{T}$ he ability to see in colour distinguishes humans from other species. However, inherited congenital colour vision defects (CVD), comprising a number of distinct disorders, are collectively relatively common. The X-linked disorder which results in difficulties in distinguishing between colours in the red/green spectrum is most common, while more severe types of CVD are rare. Although these disorders are non-progressive and untreatable, universal population screening for early identification of affected children is a long standing practice in many industrialised countries, primarily so that advice can be provided early about occupations for which normal colour vision is presently a requirement. ${ }^{1-3}$ The value of this practice is currently debated.

The UK Health and Safety Executive advise that certain occupations require normal colour vision, for either reasons of safety or quality of product (table 1). However, they recognise that within these broad occupation categories the specific functional requirements may vary, and therefore specialist assessment of colour vision is recommended in the specific context each job. International differences in statutory colour vision requirements identify inconsistencies in the evidence base for occupational preclusion. ${ }^{4}$ We undertook this study to investigate the impact of CVD on occupation, in order to inform this debate.

\section{METHODS}

Members of the 1958 British birth cohort, comprising everyone born in Britain in one week in 1958, have been followed at intervals, ${ }^{5}$ and despite some attrition, those remaining were representative of the original cohort, including with respect to colour vision status. This was assessed in 12534 children aged 11 years using the Ishihara pseudo-isochromatic test plates, ${ }^{1}$ as part of a standardised assessment of visual function which included corrected visual acuity. CVD was defined as the inability to identify all 24 plates. The main outcome measures were self-reported current occupation (at 33 years) and past occupations since leaving school, ${ }^{5}$ classified using CODOT, ${ }^{6}$ a comprehensive task based (rather than qualification/training based) taxonomy covering 3500 occupations in Britain. Individuals in "target" occupations (table 1) for which normal colour vision is currently a requirement were identified..$^{1-3}$

Table 1 Occupations with colour vision standards

\begin{tabular}{ll}
\hline Main reason for requirements & \\
\hline Safety & Quality of product \\
\hline Armed Forces & Colour matching, e.g. in textiles, paper, painting, and dyeing \\
Railways & Carpet warpers, weavers, and inspectors \\
Merchant shipping & Horticulture \\
Navigation & Chemical analysis using colour \\
Civil aviation & Colour television and testing/maintenance \\
Police and fire service & Fine art and colour photography \\
Electrical contracting & \\
Some other types of electrical engineering & \\
Hospital technicians and pharmacists & \\
\hline
\end{tabular}


Table 2 Comparison of men who in 1991, aged 33 years, worked in "target" occupations, according to colour vision status

\begin{tabular}{|c|c|c|c|c|c|c|c|}
\hline \multirow[b]{3}{*}{ Occupation } & \multirow{2}{*}{\multicolumn{2}{|c|}{$\begin{array}{l}\text { Normal colour } \\
\text { vision }\end{array}$}} & \multirow{2}{*}{\multicolumn{2}{|c|}{$\begin{array}{l}\text { Colour vision } \\
\text { defect }\end{array}$}} & \multirow{2}{*}{\multicolumn{3}{|c|}{$\begin{array}{l}\text { Difference in proportion } \\
\% \text { normal - \% CVD }\end{array}$}} \\
\hline & & & & & & & \\
\hline & $\bar{n}$ & $\%$ & $\bar{n}$ & $\%$ & $\%$ difference & $95 \% \mathrm{Cl}$ & $p$ value \\
\hline Armed forces* & 23 & 0.6 & 2 & 0.8 & -0.1 & -1.2 to 0.9 & 0.82 \\
\hline Transport operation* & 6 & 0.2 & 0 & 0 & 0.2 & 0.03 to 0.3 & 0.01 \\
\hline Aircraft and ships' officers* & 11 & 0.3 & 0 & 0 & 0.3 & 0.1 to 0.5 & 0.001 \\
\hline Police, fire-fighting, and protective services* & 118 & 3.2 & 6 & 2.3 & 1.0 & -0.9 to 2.8 & 0.31 \\
\hline Electrical and electronic engineering* & 15 & 0.4 & 0 & 0 & 0.4 & 0.2 to 0.6 & $<0.001$ \\
\hline Electrical fitting and wiring* & 11 & 0.3 & 1 & 0.4 & -0.07 & -0.8 to 0.7 & 0.85 \\
\hline Electrical installation and maintenance* & 74 & 2.0 & 4 & 1.5 & 0.5 & -1.0 to 2.0 & 0.50 \\
\hline Medicine, pharmacy, health diagnosing, and treatment ${ }^{*} \dagger$ & 25 & 0.7 & 4 & 1.5 & -0.8 & -2.3 to 0.7 & 0.28 \\
\hline Laboratory and engineering technology ${ }^{*} \dagger$ & 47 & 1.3 & 4 & 1.5 & -0.2 & -1.7 to 1.3 & 0.78 \\
\hline Painting and related coating $t$ & 39 & 1.1 & 3 & 1.1 & -0.06 & -1.4 to 1.2 & 0.93 \\
\hline Fibre and textile processingt & 18 & 0.5 & 0 & 0 & 0.5 & 0.3 to 0.7 & $<0.001$ \\
\hline Wood processing and paper makingt & 1 & 0.03 & 0 & 0 & 0.03 & -0.03 to 0.08 & 0.32 \\
\hline Horticulture & 23 & 0.6 & 2 & 0.8 & -0.1 & -1.2 to 0.9 & 0.82 \\
\hline Biological, chemical, and geological science $\dagger$ & 18 & 0.5 & 2 & 0.8 & -0.3 & -1.3 to 0.8 & 0.63 \\
\hline Printing, paper, and photographic processingt & 15 & 0.4 & 1 & 0.4 & 0.03 & -0.7 to 0.8 & 0.93 \\
\hline Art, sculpture, photography, and industrial designt & 21 & 0.6 & 0 & 0.4 & 0.6 & 0.3 to 0.8 & $<0.001$ \\
\hline Total in "target" occupations & 465 & 12.7 & 29 & 10.9 & 1.8 & -2.1 to 5.7 & 0.36 \\
\hline
\end{tabular}

Differences in occupation and employment by 33 years were compared by colour vision status. Sex is the only sociodemographic factor previously reported to be associated with occupational outcomes ${ }^{5}$ which is also related to CVD, and therefore these analyses were carried out separately for men and women.

This study is part of a broader programme of work approved by the Ethics Committee of the Institute of Child Health.

\section{RESULTS}

Of 12534 children tested for congenital colour vision defects, $6422(51 \%)$ were male and $6112(49 \%)$ were female. CVD affected 431 boys $(6.7 \%, 95 \%$ CI $6.1 \%$ to $7.3 \%)$ and 68 girls ( $1.1 \%, 95 \%$ CI $0.8 \%$ to $1.4 \%$ ). Distribution of distance visual acuity did not vary by colour vision status $\left(\chi^{2}\right.$ trend, $\mathrm{p}=0.12$ ). Birth weight, social class at birth, family size, and parental education were not associated with CVD.
At 33 years, $91 \%$ of men and $68 \%$ of women were in work or seeking work. ${ }^{5}$ Employment status did not differ by colour vision status $(\mathrm{p}=0.911$ and $\mathrm{p}=0.075$ for women and men respectively), and there were no significant differences in employment history, such as a period of unemployment $(\mathrm{p}=0.862$ and $\mathrm{p}=0.553$ respectively).

We found the overall occupational groups at 33 years varied significantly according to sex and by social class at birth, as reported previously. ${ }^{5}$ However, there were no differences according to colour vision status in major occupational groups. Nor did we find any evidence of an association between social class and colour vision status consistent with individuals choosing an occupation as a result of their colour vision defect-that is, choices other than that expected on the basis of educational background and social class. Analysis of "target" occupations, for which normal colour vision is conventionally considered necessary,

Table 3 Comparison of men who in 1991, aged 33 years, had ever worked in "target" occupations, according to colour vision status

\begin{tabular}{|c|c|c|c|c|c|c|c|}
\hline \multirow[b]{3}{*}{ Occupation } & \multirow{2}{*}{\multicolumn{2}{|c|}{$\begin{array}{l}\begin{array}{l}\text { Normal colour } \\
\text { vision }\end{array} \\
n=3665\end{array}$}} & \multirow{2}{*}{\multicolumn{2}{|c|}{$\begin{array}{l}\text { Colour vision } \\
\text { defect } \\
n=267\end{array}$}} & \multirow{2}{*}{\multicolumn{3}{|c|}{$\begin{array}{l}\text { Difference in proportion } \\
\% \text { normal - \% CVD }\end{array}$}} \\
\hline & & & & & & & \\
\hline & $\mathbf{n}$ & $\%$ & $n$ & $\%$ & $\%$ difference & $95 \% \mathrm{Cl}$ & p value \\
\hline Armed forces* & 136 & 3.7 & 9 & 3.4 & 0.3 & -1.9 to 2.6 & 0.77 \\
\hline Transport operation* & 8 & 0.2 & 0 & 0 & 0.2 & 0.07 to 0.4 & 0.005 \\
\hline Aircraft and ships' officers* & 36 & 1.0 & 0 & 0 & 1.0 & 0.7 to 1.3 & $<0.001$ \\
\hline Police, fire-fighting, and protective services* & 208 & 5.7 & 9 & 3.4 & 2.3 & 0.01 to 4.6 & 0.05 \\
\hline Electrical and electronic engineering* & 39 & 1.1 & 0 & 0 & 1.1 & 0.7 to 1.4 & $<0.001$ \\
\hline Electrical fitting and wiring* & 28 & 0.8 & 3 & 1.1 & -0.4 & -1.7 to 0.9 & 0.59 \\
\hline Electrical installation and maintenance* & 179 & 4.9 & 9 & 3.4 & 1.5 & -0.8 to 3.8 & 0.19 \\
\hline Medicine, pharmacy, health diagnosing, and treatment ${ }^{*} \dagger$ & 50 & 1.4 & 4 & 1.5 & -0.1 & -1.6 to 1.4 & 0.86 \\
\hline Laboratory and engineering technology ${ }^{*} \dagger$ & 26 & 3.4 & 7 & 2.6 & 0.8 & -1.2 to 2.8 & 0.43 \\
\hline Painting and related coating & 84 & 2.3 & 7 & 2.6 & -0.3 & -2.3 to 1.6 & 0.74 \\
\hline Fibre and textile processing $\dagger$ & 61 & 1.7 & 1 & 0.4 & 1.3 & 0.4 to 2.1 & 0.003 \\
\hline Wood processing and paper makingt & 9 & 0.3 & 1 & 0.4 & -0.1 & -0.9 to 0.6 & 0.74 \\
\hline Horticulture† & 75 & 2.1 & 5 & 1.9 & 0.2 & -1.5 to 1.9 & 0.84 \\
\hline Biological, chemical, and geological science $†$ & 38 & 1.0 & 4 & 1.5 & -0.5 & -2.0 to 1.0 & 0.55 \\
\hline Printing, paper, and photographic processing & 37 & 1.0 & 2 & 0.8 & 0.3 & -0.8 to 1.3 & 0.64 \\
\hline Art, sculpture, photography, and industrial designt & 52 & 1.5 & 4 & 1.5 & -0.08 & -1.6 to 1.4 & 0.92 \\
\hline Total in target occupations $\ddagger$ & 1013 & 27.6 & 60 & 22.5 & 5.2 & -0.05 to 10.4 & 0.05 \\
\hline
\end{tabular}




\section{What is already known on this topic}

- Population screening of children for congenital colour vision defects (CVD) is a long established practice in Britain, but its value is increasingly questioned

- The evidence base underlying occupational preclusion on the basis of congenital colour vision defects is limited

was restricted to men, as too few women were in these jobs. Analysis of current job at 33 years found that men with CVD were under-represented, compared to those with normal colour vision, in only some of these "target" occupations (table 2). For example, no men with CVD were employed in electrical and electronic engineering at 33 years compared to 15 men $(0.4 \%)$ with normal colour vision, (difference $0.4 \%$, $95 \%$ CI $0.2 \%$ to $0.6 \%$ ), but there was no difference in the proportion of men with or without CVD employed in the Armed Forces (difference $-0.1 \%, 95 \%$ CI $-1.2 \%$ to $0.9 \%$ ).

Findings were similar for analysis based on cohort members' report of "ever" having worked in target occupations (table 3 ). It should be noted that the number of individuals involved is small: for example, as only 106 per 10000 men with normal colour vision ever worked as electrical and electronic engineers by the age of 33 years, then only 7 in every 10000 individuals in the population might have been precluded from this occupation on the basis of their colour vision.

\section{DISCUSSION}

While the measurement of CVD by a single screening test and self-reporting of employment and occupation are potential sources of error in this study, these are outweighed by the benefits conferred by the size and representativeness of the population studied and the longitudinal study design, with colour vision status being measured before the outcomes.

Colour vision is integral to an individual's understanding of their visual world, and those with CVD can experience difficulties in everyday life. But, adaptive strategies and behaviours help to deal with any potential difficulties they face in both their professional and personal lives. Thus, the rationale for screening must remain the population-level impact of these conditions, particularly on occupational choice.

There are a number of occupations from which individuals with CVD are barred, on the basis of potential hazard to safety and/or in the interest of quality assurance in the workplace, ${ }^{1-3}$ even though the functional impact of a given congenital colour vision defect is known to depend on both its nature and severity as well as the specific visual tasks to be undertaken. ${ }^{1}$ The evidence base for these long standing occupational preclusions is not well defined. Our findings show that men with CVD were employed in many of these "target" occupations. We found that some men had been in the same "target" occupation for several years, but our study

\section{What this study adds}

- Many men with colour vision defect are able to work in occupations where normal colour vision is currently a statutory requirement

- The findings of this study support the challenge to existing screening programmes for congenital colour vision defects whose primary purpose is to advise affected children against certain careers

was not able to address how successful their careers were or the nature of any problems encountered at work. National guidance $^{1}$ emphasises the need for specific, individual occupational risk assessments based on detailed diagnostic (rather than screening) tests to identify severe CVD combined with a consideration of the precise colour dependent tasks that a given job requires. These findings strengthen the growing challenge to established population screening for these non-progressive and untreatable disorders. There is already evidence of deficiencies in the implementation of school screening for CVD, together with concerns that despite being identified, affected children remain ill informed about the occupational significance of their condition. ${ }^{3}$ Based on our findings, as well as the absence of robust work identifying the true risk of important adverse outcomes in key occupations, we suggest there is now a good case for existing screening programmes, whose primary purpose is to advise affected children against certain careers, to be discontinued. Other ways of informing young people about potential occupational difficulties and pathways for referral for specialist assessment are likely to be more useful.

\section{ACKNOWLEDGEMENTS}

We thank the following for archived data: Centre for Longitudinal Studies (Institute of Education), National Birthday Trust Fund, National Children's Bureau, City University Social Statistics Research Unit and the Data Archive distributor, SN:3138, Colchester. We thank Dr Angie Wade for her comments on an earlier draft of the paper.

\section{Authors' affiliations}

P Cumberland, J S Rahi, C S Peckham, Institute of Child Health, London, UK

Competing interests: none declared

\section{REFERENCES}

1 Health and Safety Executive. Colour vision. Medical Series Guidance Notes, MS7. London: HMSO, 1987:1-8.

2 Taylor WOG. Effects on employment of defects in colour vision. Br J Ophthalmol 1971;55:753-60.

3 Holroyd E, Hall DMB. A re-appraisal of screening for colour vision impairments. Child Care Health Dev 1997;23:391-8.

4 Cole BL. The handicap of abnormal colour vision. Clin Exp Optom 2004;87:258-75

5 Ferri E. Life at 33. The fifth follow-up of the National Child Development Study. London: National Children's Bureau, 1993.

6 Department of Employment. Classification of Occupations and Directory of Occupational Titles (CODOT). London: HMSO, 1972. 